\title{
Identification of odors of edible and nonedible stimuli as affected by age and gender
}

\author{
ANNA Fusari AND SOledad BaLlesteros \\ Universidad Nacional de Educación a Distancia, Madrid, Spain
}

\begin{abstract}
This study investigated cued odor identification performance with a set of 64 natural common odors (half of edible and half of nonedible stimuli) in three groups of participants: one group of 30 young adults (mean age 25.3 years, range 18-30,SD 3.1) and two groups of older adults - 20 young-old (mean age 64.4 years, range 60-69, $S D 2.8$ ) and 21 old-old (mean age 74.6 years, range 70-79, SD 2.5). The results showed that 49 of the 64 odors were correctly identified by over $70 \%$ of the participants in all groups. The odor identification performance of the young-old adults did not differ from that of the young adults. However, the oldest group showed a significant loss of performance in the task. Women in the young-old group performed better than men, whereas no gender differences were found in the other two age groups. The data obtained in this study will be useful for further perceptual and memory studies conducted in the olfactory modality with young as well as with older participants.
\end{abstract}

Several studies have provided useful normative data for different kinds of materials, such as familiar pictures (e.g., Snodgrass \& Vanderwart, 1980), verbal stimuli (e.g., Bachoud-Lévi, Dupoux, Cohen, \& Mehler, 1998; Cuetos, Ellis, \& Alvarez, 1999; Jescheniak \& Levelt, 1994), and fragmented written words (e.g., Reales, Ballesteros, \& García, 2002). These studies have proven to be very useful in selection of the stimuli to be used in visual and auditory implicit and explicit memory studies. Most such studies have been conducted on vision (e.g., Ballesteros, Reales, \& García, 2007; Ballesteros, Reales, García, \& Carrasco, 2006; Ballesteros, Reales, \& Mayas, 2007; Parkin \& Russo, 1990), but sometimes stimuli have been presented haptically at study and visually at test (e.g., Reales $\&$ Ballesteros, 1999). Normative studies are needed in other perceptual modalities, such as olfaction. The results from such studies would be very useful in the selection of odor stimuli for perception and implicit memory investigations (e.g., Fusari \& Ballesteros, 2006).

The main goal of the present study was to gather precise information on olfactory identification performance using a large set of odors from edible and nonedible natural common substances familiar to Spaniards. The second important goal of this study was to compare odor identification performance in young adults and older healthy adults, since sensorial losses are known to increase with age and, consequently, olfactory acuity is known to decrease. A number of studies have indicated that normal aging is associated with a decrease in ability to identify odor information (Doty, Shaman, Applebaum, et al., 1984; Larsson, Finkel, \& Pedersen, 2000; Larsson, Nilsson, Olofsson, \& Nordin, 2004), although not all studies have reported age differences in olfactory performance (Rovee, Cohen, \& Shlapack, 1975).
The large set of edible and nonedible olfactory stimuli used in the present study will make it very useful for olfaction researchers interested in studying perception and memory processes in young and older adults.

Several studies using psychophysical measurements have shown an age-related olfactory performance decline in tasks such as odor detection (Murphy, 1983), odor identification (Murphy \& Cain, 1986), and odor memory (Murphy, Cain, Gilmore, \& Skinner, 1991; Murphy, Nordin, \& Acosta, 1997). The causes of this decline are not completely understood, although it has been attributed to anatomical changes in some peripheral olfactory structures, such as a decrease in the number of receptors that converge in the olfactory bulb, in mitral cells, and in central olfactory areas such as the temporal lobe, the entorhinal cortex, the hippocampus, and the amygdala (Cowell et al., 1994; Kaneda et al., 2000; Price, Davis, Morris, \& White, 1991). Previous research has shown that olfactory performance depends highly on the task used to assess odor performance. Adult observers are quite poor in naming common odors without the help of contextual cues. Naming performance for common odors is usually not higher than $50 \%$ correct and only very rarely reaches $90 \%$ (Cain, 1979; Desor \& Beauchamp, 1974; Jönsson \& Olsson, 2003). Accuracy improves considerably, however, when participants are provided with contextual cues and in each trial are required to select the target odor stimulus from a list of odorants in a multiple forced choice odor identification task (Larsson et al., 2004). For this reason, in the present study we used the cued odor identification task.

Most studies on odor identification have used a rather small set of stimuli, ranging from 2 to 16 odors (Finkel, Pedersen, \& Larsson, 2001; Kaneda et al., 2000; Larsson et al., 2004; Nordin, Nyroos, Maunuksela, Niskanen, \& 
Tuorila, 2002; Suzuki et al., 2004; Westervelt, Ruffolo, \& Tremont, 2005). Although some odor perception studies have used standardized and commercially available olfactory tests, they have shown cultural differences that limit the generalizability of their results. Among the odor identification tests used in clinical and experimental studies to assess odor performance are the University of Pennsylvania Smell Identification Test (UPSIT; Doty, Shaman, Kimmelman, \& Dann, 1984) and the Connecticut Chemosensory Clinical Research Center Identification Test (Cain, 1989), both of which were developed in the United States. Other tests are the Sniffin' Sticks (Kobal et al., 1996), the Scandinavian Odor-Identification Test (Nordin, Brämerson, Lidén, \& Bende, 1998), and the Biolfa Olfactory Test (Bonfils, Faulcon, \& Avan, 2004).

Odor identification is closely related to familiarity and experience with the stimuli (Cain, 1970). For example, some researchers (Parola \& Liberini, 1999; Takagi, 1989) have reported cultural differences when administering some of the commercially available tests. To address these cultural effects, Doty, Marcus, and Lee (1996) developed the 12-item Cross-Cultural Smell Identification Test, which consists of the most familiar items of the UPSIT. However, some odors from the UPSIT test are unfamiliar to certain European populations. Odor familiarity and odor name familiarity remain fundamental problems for olfactory research. In sum, crosscultural differences raise the question of whether a single set of odors can be successfully used in different countries. As has been claimed, language and cultural boundaries cannot be crossed with impunity while administering and interpreting odor identification performance (Frank, Dulay, \& Gesteland, 2003). Other researchers have tried to explain differences between cultures in terms of olfactory ability and odor preferences. However, learning may also play an important role in olfactory performance (Alaoui-Ismailli, VernetMaury, Dittmar, Delhomme, \& Chanel, 1997; Engen, 1988; Lehrner, Glück, \& Laska, 1999).

In addition to cultural differences, the ability to perceive an odor varies widely among individuals. Interindividual differences are, in part, attributable to age, smoking habits, gender, or health problems. In some studies, researchers have pointed out that nonsmokers show greater acuity than smokers (Frye, Schwartz, \& Doty, 1990), whereas others have reported nonsignificant differences between smokers and nonsmokers (Double et al., 2003).

Gender is another variable that influences odor identification. Women have been found, on average, to possess a keener sense of smell than men, and this superiority has been shown to exist from the age of 4 (Doty, 1986; Doty, Applebaum, Zusho, \& Settle, 1985; Doty, Shaman, Applebaum, et al., 1984; Liu et al., 1995). Moreover, women retain their superior ability longer than men (Doty, Shaman, Applebaum, et al., 1984). Some studies have also shown that odor detection varies with the menstrual cycle, with maximum sensitivity at the time of ovulation and lowest sensitivity during a woman's period (Doty, Snyder, Huggins, \& Lowry, 1981; Richardson \& Zucco, 1989).

Not all studies, however, have shown gender differences in olfactory performance. For example, Larsson et al. (2000) found that although women showed slightly better performance than men, gender did not reach significance in either an odor identification or odor detection task. As these authors pointed out, it is difficult to explain gender differences on olfactory tasks with cross-sectional studies, and in the olfactory domain, longitudinal studies have been the exception rather than the rule.

Gender differences in olfactory tasks have also been shown in brain imaging studies. Using fMRI, Yousem et al. (1999) showed that women activated up to eight times more voxels in the frontal and temporal lobes than men when exposed to the same odorants. These authors highlighted the importance of controlling for gender effects in studies with olfactory stimulants. Royet, Plailly, DelonMartin, Kareken, and Segebarth (2003) found different patterns of brain activation in males and females when the two groups smelled odors passively or performed odor hedonic judgments; although men showed bilateral activation of the insula, women also had activation in the left orbitofrontal cortex. This part of the brain, closely related to language areas, may contribute heavily to women's superior performance. Furthermore, a number of studies have reported that women performed better than men in episodic recognition for olfactory and verbal information. The observed female superiority disappeared when verbal proficiency was taken into account. In the same line, Doty and Kerr (2005) used a 12-item odor memory test administered separately to the left and right sides of the nose. They found that women performed better on the left than on the right side of the nose, whereas men did not show such a left-right difference. These results suggest that women may rely on semantic-related encoding and/or retrieval processes, since women employ more semantic strategies than men do in remembering odors (Larsson, Lövdén, \& Nilsson, 2003; Öberg, Larsson, \& Bäckman, 2002) and the left hemisphere is more involved in language processing than the right one (Beaton, 1985).

In this article, we report a study in which 71 Spanish participants (30 young adults and 41 healthy older adults) performed a forced choice identification task with a set composed of 64 common odors, half from edible and half from nonedible items. The cultural differences observed in several odor studies make the results of the present study useful. Although it is generally accepted that naming tasks may be influenced by verbal abilities, in the present study we used a cued identification task that is less dependent on verbal skills. The gender influence on odor identification in young and older healthy adults is also reported, along with the percentages of correct identification performance with the edible and nonedible stimuli for young, young-old, and old-old adults (see Table 5 in the Results). These data would be useful in the selection of odor stimuli for future odor perception and memory studies conducted with young and older participants. Furthermore, these results would be most useful for the selection of stimuli to be used in further olfactory perceptual-priming studies, as well as in multisensory integration studies, cross-modal perception studies, and memory experiments. As far as we know, no other study has collected normative data for a large set of ecologically valid odor stimuli with young and older Spanish adults. 
Table 1

Participant Characteristics

\begin{tabular}{|c|c|c|c|c|c|c|}
\hline \multirow[b]{2}{*}{ Gender } & \multicolumn{2}{|c|}{$\begin{array}{c}\text { Young Adults } \\
n=30(15 / 15)\end{array}$} & \multicolumn{2}{|c|}{$\begin{array}{l}\text { Young-Old Adults } \\
n=20(10 / 10)\end{array}$} & \multicolumn{2}{|c|}{$\begin{array}{l}\text { Old-Old Adults } \\
n=21(11 / 10)\end{array}$} \\
\hline & $M$ & $S D$ & $M$ & $S D$ & $M$ & $S D$ \\
\hline \multicolumn{7}{|c|}{ Age (Years) } \\
\hline Males & 24.60 & 3.56 & 64.30 & 3.06 & 74.36 & 2.33 \\
\hline Females & 26.13 & 2.80 & 64.60 & 2.63 & 74.90 & 2.73 \\
\hline \multicolumn{7}{|c|}{ Years of Education } \\
\hline Males & 14.20 & 3.06 & 14.50 & 2.76 & 10.64 & 1.96 \\
\hline Females & 13.80 & 2.78 & 8.60 & 4.57 & 9.40 & 7.78 \\
\hline
\end{tabular}

Note-Numbers in parentheses indicate the numbers of males/females.

\section{METHOD}

\section{Participants}

The study included 30 young adult (18-30 years) and 41 older adult (60-79 years) participants. The older adult group was further divided into two subgroups: The young-old group consisted of 20 participants (10 men and 10 women) from 60 to 69 years of age and the old-old group of 21 participants ( 11 men and 10 women) from 70 to 79 years of age. The gender distribution and years of formal education across age groups are shown in Table 1 . The young adults were volunteer undergraduate students and clerical workers at Universidad Nacional de Educación a Distancia (UNED). The two older adult groups were recruited from several day centers for elderly adults and residential care homes in several areas of Spain. All participants reported normal health and the absence of anosmia. All were asked not to wear any fragrance and to avoid smoking for at least $3 \mathrm{~h}$ before the experimental session. The study was approved by the University Ethics Committee, and participants signed an informed consent form before the experiment started.

\section{Materials and Equipment}

The stimuli used in the present study were 64 common odors. Only real-world substances were used to produce the odor stimuli. These stimuli were selected in a previous pilot study, in which 32 blindfolded participants were presented with a larger set of real-world substances and had to rate them on edibility, familiarity, and ease of naming before performing a multiple-choice identification task. In a posttest interview, the participants were asked which of the three variables (i.e., edibility, familiarity, and ease of naming) was the easiest to rate. Twenty-four out of the 30 participants who completed the study indicated that edibility was the easiest, whereas 6 selected familiarity.
Only stimuli those participants rated as extremely high in familiarity and ease of naming as well as extremely high or low in edibility were included in the present study (Koenig, Bourron, \& Royet, 2000).

The total set of 64 stimuli was randomly divided into two subsets of 32 odors each (see Table 2). Half of the stimuli corresponded to edible and the other half to nonedible substances. In order to avoid tiredness and habituation, these two sets were presented in two different experimental sessions. The presentation order of the two sets was counterbalanced across participants. To ensure freshness and odor strength, every $24 \mathrm{~h}$ the old stimulus substances were replaced by new ones. The intensity of all of the stimuli was quite strong and perceptually salient.

Each substance was placed in an opaque, $500-\mathrm{ml}$ plastic jar provided with a hermetic lid. The substance filled less than one third of the total volume of the jar, leaving the other two thirds available for smelling and providing an adequate olfactory microclimate. Although the jars were opaque, they were also wrapped with white tape to ensure a complete lack of visibility. Table 2 shows a list of the stimuli used in the present study.

\section{Experimental Design}

The experimental design consisted of a 3 (group: young adults and the two older adult groups) $\times 2$ (gender: male or female) $\times 2$ (item type: edible or nonedible stimuli) mixed factorial design. The first two variables were manipulated between subjects, whereas the last was the within-subjects variable.

\section{Procedure}

All participants were tested individually by the same experimenter in a quiet, slightly darkened, and well-ventilated room. They participated in two experimental sessions that lasted approximately $45 \mathrm{~min}$ each. Both sessions took place on the same day, separated by at least $2 \mathrm{~h}$. To avoid visual interference, the participants wore black opaque plastic glasses during the sessions. The experimental task was cued odor identification. For each stimulus, the experimenter provided the participant with a list of four response alternatives from which he or she could select the most appropriate one. In order to avoid ceiling effects, along with the right answer we included a similar one (e.g., "garlic" and "onion" for garlic) and two quite different ones (e.g., "olives" and "vinegar" for garlic).

The 64 odor stimuli were randomly divided into two sets of 32 stimuli each. These sets were counterbalanced across participants. Half of the stimuli in each set were for edible and the other half for nonedible substances. The stimuli in both sets were presented in a different random order to each participant. When a participant entered the room, he or she was asked to wear the black glasses. Then the experimenter opened a jar and placed it in the participant's hands, asking him or her to smell the odor birhinally for as long as

Table 2

List of Olfactory Stimuli Used in the Present Study

\begin{tabular}{|c|c|c|c|}
\hline \multicolumn{2}{|c|}{ Set 1} & \multicolumn{2}{|r|}{ Set 2} \\
\hline Edible & Nonedible & Edible & Nonedible \\
\hline Anis liquor & Vicks VapoRub & Ground coffee & Lavender \\
\hline Coca-Cola & Marking pen & Nutmeg & Nail polish remover \\
\hline Oregano & Mistol dish soap & Black tea & Cristasol window cleaner \\
\hline Lager beer & Alcohol & Orange & Paint \\
\hline Granny Smith apple & Nenuco cologne & Mint leaves & Nivea cream \\
\hline Olive oil & Jasmine flowers & Onion & Pine extract \\
\hline Orgeat & Pronto cleaner & Lemon & Marsella laundry soap \\
\hline Banana & Chamomile flowers & Sheep cheese & Gasoline \\
\hline Clove & Magno shower gel & Chocolate & Imedio glue \\
\hline Chorizo sausage & Heno de Pravia soap & Cinnamon & Herbal \\
\hline Cognac & Leather & Garlic & Licorice root \\
\hline Ham & 3-in-1 lubrication oil & Peach & Rose \\
\hline Peanuts & Shoe polish & Snacks & Canary seeds \\
\hline Strawberry & Talcum powder & Tomato & Cigarette butts \\
\hline Tuna fish & Colgate toothpaste & Vinegar & Turpentine \\
\hline Red wine & Camphor & Thyme & Lilac flowers \\
\hline
\end{tabular}


Table 3

Response Alternatives for the Edible and Nonedible Stimuli

\begin{tabular}{|c|c|c|c|}
\hline \multicolumn{2}{|r|}{ Edible } & \multicolumn{2}{|r|}{ Nonedible } \\
\hline Stimuli & Response Alternatives & Stimuli & Response Alternatives \\
\hline Anis & Anis, lemon, cologne, wine & Alcohol & Vinegar, wine, soap, alcohol \\
\hline Apple & Pear, almond, apple, strawberry & Baby cologne & Baby cologne, coffee, gasoline, vinegar \\
\hline Banana & Pineapple, pear, vanilla, banana & Bird food & Peanuts, strawberry, bird food, camphor \\
\hline Beer & Beer, wine, Coca-Cola, anis & Chamomile flowers & Lavender, pine, mint, chamomile flowers \\
\hline Black tea & Coffee, tea, peppermint, black pepper & Camphor & Vinegar, camphor, lemon, chocolate \\
\hline Cheese & Ham, olive oil, cheese, olives & Dish detergent & Acetone, wine, licorice, dish detergent \\
\hline Chocolate & Chocolate milk mix, chocolate, coffee, vanilla & Furniture cleaner & Furniture cleaner, wine, orange, coffee \\
\hline Chorizo & Chorizo, cheese, olive oil, fish & Gasoline & Gasoline, nail polish remover, vinegar, wine \\
\hline Cinnamon & Ham, chocolate, violet, cinnamon & Glue & Glue, laundry soap, lemon, rose \\
\hline Clove & Rose, clove, vanilla, soap & Heno de Pravia soap & Vanilla, coffee, Heno de Pravia, wine \\
\hline Coca-Cola & Wine, orange juice, Coca-Cola, anis & Herbal shampoo & Rose, cherry, vinegar, herbal \\
\hline Coffee & Potato chips, chocolate milk mix, chocolate, coffee & Jasmine & Pine, jasmine, violet, chocolate \\
\hline Cognac & Anis, cognac, wine, rose & Lavender & Lavender, tobacco, mint, cheese \\
\hline Garlic & Olives, garlic, vinegar, onion & Leather & Anis, marking pen, coffee, leather \\
\hline Ham & Ham, olive oil, cheese, apple & Licorice root & Licorice root, chocolate, orange, apple \\
\hline Lemon & Wine, orange, cheese, lemon & Lilac flowers & Lilac, rose, pine, vinegar \\
\hline Mint & Coconut, mint, lavender, cheese & Lubricating oil & Lubricating oil, olive oil, wine, toilet soap \\
\hline Nutmeg & Nutmeg, clove, apple, curry & Marking pen & Laundry soap, turpentine, lemon, marking pen \\
\hline Olive oil & Cheese, soap, olive oil, wine & Marsella laundry soap & Marsella soap, orange, tobacco, strawberry \\
\hline Onion & Garlic, vinegar, eucalyptus, onion & Nail polish remover & Gasoline, nail polish remover, vinegar, apple \\
\hline Orange & Orange, lemon, pineapple, tobacco & Nivea cream & Nivea cream, vanilla, chocolate, tobacco \\
\hline Oregano & Black pepper, peppermint, camphor, oregano & Paint & Gasoline, apple, wine, paint \\
\hline Orgeat & Strawberry, orgeat, wine, vinegar & Pine & Strawberry, vinegar, pine, camphor \\
\hline Peach & Banana, apple, peach, gasoline & Rose & Pine, vanilla, chocolate, rose \\
\hline Peanuts & Strawberry, peanuts, chocolate, cinnamon & Shoe polish & Shoe polish, cologne, apple, tobacco \\
\hline Snacks & Snacks, cherry, bacon, coffee & Shower gel & Tobacco, shower gel, leather, vinegar \\
\hline Strawberry & Strawberry, apple, camphor, orange & Talcum powder & Talcum powder, lemon, oregano, coffee \\
\hline Thyme & Coffee, tea, chocolate, thyme & Tobacco & Coffee, camphor, peanut, tobacco \\
\hline Tomato & Tomato, orange juice, cherry, strawberry & Toothpaste & Lemon, anis, toothpaste, herbal shampoo \\
\hline Tuna fish & Tomato, tuna fish, olive oil, cheese & Turpentine & Vinegar, pine, wine, turpentine \\
\hline Vinegar & Anis, cologne, gasoline, vinegar & Vicks VapoRub & Vicks VapoRub, orange, alcohol, apple \\
\hline Wine & Gasoline, wine, orange juice, mint & Window cleaner & Window cleaner, lemon, tobacco, gasoline \\
\hline
\end{tabular}

required to perform the task. When the participant started to smell the odor, the experimenter read a list of four response alternatives, and the participant was asked to select the most appropriate one (see Table 3). After each trial, the experimenter registered the response. The interstimulus interval was $60 \mathrm{sec}$, to avoid adaptation effects. No feedback on performance was provided during the task. The number of correct responses was the dependent variable.

\section{RESULTS AND DISCUSSION}

The numbers of correct odor identifications were submitted to a 3 (age group: young, young-old, and old-old adults) $\times 2$ (gender: male or female) $\times 2$ (item types: edible or nonedible stimuli) ANOVA. Table 4 displays the mean numbers of odors correctly identified across age groups, genders, and types of odor. The main effect of group was highly significant $\left[F(2,65)=30.86, M S_{\mathrm{e}}=\right.$ $138.44, p<.001]$. Post hoc comparisons between the groups showed that the old-old group performed worse (mean 22.12) than both the young (mean 25.33, $p<.001$ ) and young-old (mean 24.88, $p<.001$ ) groups, which did not differ significantly $(p>.05)$. Gender was also significant $\left[F(1,65)=5.11, M S_{\mathrm{e}}=22.93, p=.027\right]$, with women performing better than men (means 24.52 and 23.70 , respectively). Item type was also highly significant $\left[F(1,65)=15.68, M S_{\mathrm{e}}=51.55, p<.001\right]$, showing that edible stimuli were identified more accurately than nonedible stimuli (means 24.72 and 23.49, respectively).

The interaction between group and gender was also statistically significant $\left[F(2,65)=7.51, M S_{\mathrm{e}}=33.70, p=\right.$ $.001]$. The analysis of this interaction showed that women in the young-old group performed better than men $(p<$ .001 ), whereas the genders in the other two age groups did not differ significantly (see Figure 1).

The interaction between group and item type was also significant $\left[F(2,65)=8.035, M S_{\mathrm{e}}=26.41, p<.001\right]$,

Table 4

Mean Numbers of Odors Correctly Identified (and Standard Deviations) As a Function of Group, Gender, and Type of Odor

\begin{tabular}{lcclll}
\hline & \multicolumn{2}{c}{ Edible } & & \multicolumn{2}{c}{ Nonedible } \\
\cline { 2 - 3 } \cline { 5 - 6 } Group & $M$ & $S D$ & & $M$ & $S D$ \\
\hline Young Adults & & & & \\
$\quad$ Male $(n=15)$ & 27.00 & 1.77 & & 23.93 & 2.15 \\
$\quad$ Female $(n=15)$ & 26.53 & 1.51 & & 23.87 & 2.00 \\
Young-Old Adults & & & & \\
$\quad$ Male $(n=10)$ & 23.40 & 1.89 & & 23.50 & 1.18 \\
$\quad$ Female $(n=10)$ & 26.60 & 2.01 & & 26.00 & 1.89 \\
Old-Old Adults & & & & \\
$\quad$ Male $(n=11)$ & 22.09 & 2.21 & & 22.27 & 1.35 \\
$\quad$ Female $(n=10)$ & 22.70 & 2.91 & & 21.40 & 2.46 \\
\hline
\end{tabular}

Note-The maximum number of correct identifications is 32 . 


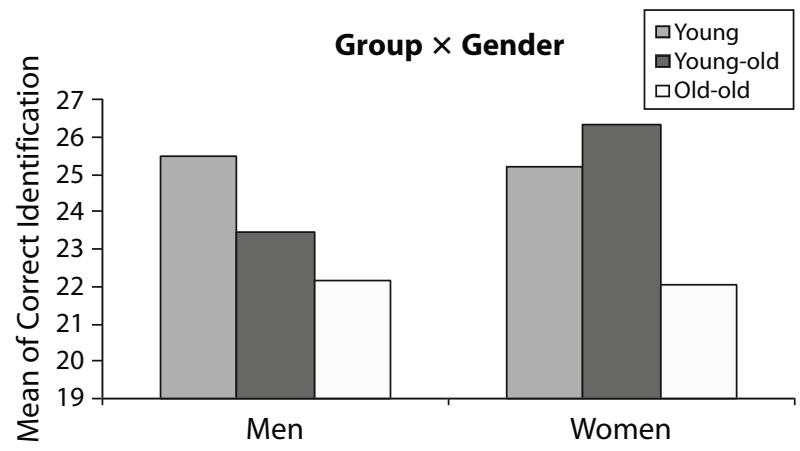

Figure 1. Group $\times$ gender interaction. Women in the young-old group (60-69 years of age) outperformed men, whereas the odor performance of men and women in the other two groups did not differ.

indicating that young adults identified edible better than nonedible stimuli $(p<.001)$, whereas the two older groups did not differ $(p=.652$ and .325 for the youngold and old-old groups, respectively).

The percentages of correct odor identification performance for edible and nonedible stimuli across the three age groups are shown in Table 5.

As is shown there, some odors were easier to identify than others. A total of 49 of the 64 odors were identified correctly by more than $70 \%$ of the participants in all groups, whereas 15 odors (clove, Coca-Cola, dish detergent, jasmine, leather, lilac, marking pen, nail polish remover, nutmeg, orange, oregano, paint, shower gel, thyme, and window cleaner) showed lower identification performance. Since the number of possible answers was four, the chance performance level was $25 \%$ correct. Young adult participants performed below chance level with 5 odors (i.e., nutmeg $7 \%$, thyme $9 \%$, lilac $13 \%$, clove $13 \%$, and jasmine $23 \%$ correct). The two older adult groups identified below chance level for nutmeg (16\%), lilac (18\%), and thyme (23\%). Coca-Cola, oregano, and nail polish remover were identified well by young adults $(85 \%, 77 \%$, and $77 \%$ correct, respectively), whereas the percentages of correct identifications by the older groups were much lower $(40 \%, 50 \%$, and $37 \%$ correct, respectively). Coffee and garlic (edible stimuli) were the easiest to identify for the three groups. From the set of 32 nonedible stimuli, gasoline and tobacco were identified most accurately by the three groups (see Table 5).

The major goal of the present study was to examine the cued odor identification performance of young adults and of older adults in two age groups using a wide range of common edible and nonedible olfactory stimuli. As far as we know, this is the first study employing a large set of edible and nonedible natural stimuli with this range of young and older healthy perceivers. We used 64 odors that were representative of a wide range of familiar aromatic qualities (e.g., floral, citric, fruity, sweet, woody, spicy, minty, and pungent). The results could be very useful in the selection of odor stimuli for perceptual and memory studies with young and older participants.

Overall, the cued odor identification performance of young adults and young-old adults was similar and quite good ( $79 \%$ and $78 \%$, respectively). However, there was a significant age-related decline in performance. The lower performance observed in the old-old group (69\%) might be specific to olfaction, or it might be part of a more general deficit. The overall performance obtained in the present study is in accordance with other studies that have used a multiple forced choice identification paradigm (Devanand et al., 2000; Nordin et al., 2002). Frank et al. (2003) suggested that even perceivers with excellent olfactory acuity have difficulty naming odors in an uncued naming task. In contrast, the multiple-choice odor identification task requires less cognitive effort, because participants are provided with several response alternatives from which to choose the correct one. In our study, participants were provided with four alternatives to choose among. The present results showed that 49 of a set of 64 olfactory stimuli were correctly identified by over $70 \%$ of the participants.

Liss and Gomez (1958) conducted an early study that investigated age-related general decrements in smell sensitivity. The results showed that senile degenerative changes occur in the central nervous system, including extensive degeneration of the olfactory epithelium, with subsequent degeneration of the olfactory bulb. Years later, Doty, Shaman, Applebaum, et al. (1984) indicated that, since the causes of the morphological changes in olfactory bulbs with age are unknown, the evidence that regressive bulbs may be involved in inducing diminished smell perception is only circumstantial. Age-related sensorial losses may also depend on the atrophy of olfactory receptors, increased exposure to harmful chemicals in the environment, as well as to an increased probability of complications arising from other age-related diseases and from medication (Bhatnagar, Kennedy, Baron, \& Greenberg, 1987).

A number of olfactory studies using naming odor identification tasks have shown consistent age-related odor identification impairments in the elderly. In the present study, the performance of the oldest group was significantly worse than that of the two younger groups. Nevertheless, the mean correct identification performance was $79 \%$ and $69 \%$ correct for the young-old and old-old adult groups, respectively. These results support Larsson and Bäckman's (1997) findings that older adults would benefit selectively from semantic support at retrieval (e.g., multiple-choice response alternatives). These researchers suggested that age-related deficits in odor naming most likely reflect accessibility problems. Murphy et al. (1991) also pointed out that any cognitive contribution to impaired odor identification performance will depend on the task's demands. In this sense, the multiple forced choice odor identification task makes lower cognitive demands than the naming task. Other studies have shown better odor identification performance using multiple-choice tests (Doty, Shaman, Applebaum, et al., 1984). Task selection is especially important in studies conducted with older perceivers (Doty, Shaman, \& Dann, 1984; Eskenazi, Cain, \& Friend, 1986). Suzuki et al. (2004) compared the utility of two olfactory tests, the Picture-Based Smell Identification Test (P-SIT) and the Cross-Cultural Smell Identification Test (CC-SIT), as possible clinical markers and found substantial differences in the identification performance of older people. The correct identification percentage obtained by the healthy 
Table 5

Percentages of Correct Identification Performance for Edible and Nonedible Stimuli for Young (18-30 Years of Age), Young-Old (60-69), and Old-Old (70-79) Adults

\begin{tabular}{|c|c|c|c|c|c|c|c|}
\hline Edible & $\begin{array}{l}\text { Young } \\
\text { Adults }\end{array}$ & $\begin{array}{l}\text { Young- } \\
\text { Old }\end{array}$ & $\begin{array}{l}\text { Old- } \\
\text { Old }\end{array}$ & Nonedible & $\begin{array}{l}\text { Young } \\
\text { Adults }\end{array}$ & $\begin{array}{c}\text { Young- } \\
\text { Old }\end{array}$ & $\begin{array}{l}\text { Old- } \\
\text { Old }\end{array}$ \\
\hline Anis & 83 & 73 & 70 & Alcohol & 84 & 87 & 77 \\
\hline Apple & 80 & 70 & 70 & Baby cologne & 77 & 73 & 70 \\
\hline Banana & 93 & 73 & 70 & Bird food & 83 & 80 & 77 \\
\hline Beer & 80 & 83 & 70 & Chamomile flowers & 77 & 83 & 77 \\
\hline Black tea & 77 & 80 & 73 & Camphor & 80 & 90 & 90 \\
\hline Cheese & 87 & 73 & 70 & Dish detergent & 29 & 37 & 50 \\
\hline Chocolate & 80 & 77 & 70 & Furniture cleaner & 77 & 73 & 70 \\
\hline Chorizo & 93 & 83 & 77 & Gasoline & 100 & 93 & 97 \\
\hline Cinnamon & 90 & 70 & 70 & Glue & 80 & 70 & 73 \\
\hline Clove & 13 & 53 & 63 & Heno de Pravia soap & 83 & 83 & 73 \\
\hline Coca-Cola & 85 & 50 & 30 & Herbal shampoo & 80 & 77 & 70 \\
\hline Coffee & 100 & 96 & 100 & Jasmine & 23 & 47 & 60 \\
\hline Cognac & 93 & 73 & 83 & Lavender & 77 & 77 & 73 \\
\hline Garlic & 96 & 100 & 97 & Leather & 73 & 73 & 63 \\
\hline Ham & 83 & 70 & 73 & Licorice root & 77 & 73 & 70 \\
\hline Lemon & 87 & 83 & 73 & Lilac flowers & 13 & 23 & 13 \\
\hline Mint & 87 & 83 & 73 & Lubricating oil & 77 & 70 & 73 \\
\hline Nutmeg & 7 & 19 & 13 & Marking pen & 47 & 33 & 23 \\
\hline Olive oil & 90 & 87 & 70 & Marsella soap & 80 & 83 & 77 \\
\hline Onion & 93 & 87 & 80 & Nail polish remover & 77 & 50 & 23 \\
\hline Orange & 67 & 50 & 13 & Nivea cream & 80 & 83 & 80 \\
\hline Oregano & 77 & 67 & 33 & Paint & 77 & 67 & 70 \\
\hline Orgeat & 78 & 73 & 70 & Pine & 80 & 73 & 70 \\
\hline Peach & 87 & 77 & 70 & Rose & 77 & 77 & 70 \\
\hline Peanuts & 93 & 93 & 77 & Shoe polish & 80 & 70 & 83 \\
\hline Snacks & 87 & 70 & 70 & Shower gel & 57 & 67 & 70 \\
\hline Strawberry & 90 & 70 & 73 & Talcum powder & 77 & 73 & 77 \\
\hline Thyme & 9 & 13 & 33 & Tobacco & 100 & 97 & 97 \\
\hline Tomato & 93 & 93 & 87 & Toothpaste & 87 & 77 & 70 \\
\hline Tuna fish & 83 & 77 & 70 & Turpentine & 75 & 70 & 70 \\
\hline Vinegar & 100 & 97 & 93 & Vicks VapoRub & 87 & 83 & 87 \\
\hline Wine & 97 & 90 & 87 & Window cleaner & 77 & 60 & 77 \\
\hline
\end{tabular}

older adult group in the P-SIT (6 odors) was $73 \%$, whereas in the CC-SIT (12 odors), the correct identification percentage dropped to $57 \%$. The researchers concluded that an easier test, such as the P-SIT, which uses pictures as cues, facilitates olfactory identification. Nordin et al. (1998), in a validation study, obtained a rather wide range of correct identifications (from 18\% to $70 \%$ correct) in a naming task. These authors concluded that performance would improve considerably if response alternatives were provided.

Olfactory sensorial losses among the healthy elderly are not always reflected by impaired performance in odor identification tasks. Other studies employing cued identification tasks have obtained better older adult performance. In a recent study with older adults, Nordin et al. (2002) used 16 natural odors and found $81 \%$ correct identifications. Similarly, Devanand et al. (2000) assessed the predictive utility of olfactory identification deficits and showed that older healthy adults identified $88 \%$ of the odors correctly.

In the present study, using a cued odor identification task and a set of edible and nonedible stimuli, the performance of young adults ( $79 \%$ correct) did not differ from that of the young-old group (78\% correct). These findings suggest that aged participants' performance in the olfactory identification task may be comparable to younger adults' performance, since no sign of odor identification decrease was found. In contrast, the old-old adult group (composed of participants $70-79$ years of age) performed significantly worse than the two younger groups (only $69 \%$ correct on average). This result is in accord with previous findings. For example, in Doty's (1989) research, more than half of participants between 65 and 80 years old, and over three quarters of those older than 80 , showed such impairment. Similarly, Finkel et al. (2001) also showed that older adult participants correctly identified less than $40 \%$ of the 6 odors of the smell survey. More recently, Koskinen and Tuorila (2005) found that the elderly successfully identified only $66.2 \%$ of 16 artificial odors. Similar levels of performance were reported in another recent study conducted by Westervelt et al. (2005), in which olfaction was assessed in a neuropsychological examination with older participants. There, identification performance in the Brief Smell Identification Test was $68.5 \%$ correct.

Therefore, the olfactory performance of our two older adult groups suggests an age-related decrement in odor identification performance, but only in the oldest group (70-79 years of age). A performance decline was not evident in the young-old group (60-69 years of age), because these old participants performed similarly to the young adults.

Gender is another variable that differentiates odor performance. A number of studies have reported superior odor performance in women as compared with men (Barber, 1997; Corwin, Loury, \& Gilbert, 1995; Doty, Shaman, Applebaum, et al., 1984; Larsson et al., 2003; Larsson et al., 2004; Lehrner, 1993; Richman, Wallace, \& Sheehe, 1995; 
Ship, Pearson, Cruise, Brant, \& Metter, 1996). Our results did show a gender effect that was qualified by the interaction between gender and age, indicating that females in the young-old group (ages 60-69) performed better than males of the same age with both edible and nonedible stimuli. In the other two groups, performance did not differ between men and women. No gender differences were found in the older group (ages 70-79). In the latter group, some women subjectively reported at the end of the experimental sessions a loss of experience with certain odors, suggesting that physical and experiential factors might have negatively affected their performance in the task. As Murphy et al. (1991) pointed out, "Aging requires a more-or-less continual updating of familiarity. Somewhere along the line, however, the updating apparently begins to fail, despite more years of cumulative experience with the stimulus materials" (p. 184). However, the unexpected absence of gender differences in the present study within the young adult group may reflect a small sample size in this task.

Other complex psychological, physiological, and experiential factors might also affect smell perception, making it difficult to find a direct relationship between age and smell sensitivity. Possibly the factors contributing to agerelated olfactory impairments are complex, and therefore potentially interacting. The effects of aging in olfaction are heterogeneous, as a number of studies have shown (Larsson \& Bäckman, 1997; Larsson et al., 2000; Murphy et al., 1991; Schemper, Voss, \& Cain, 1981; Schiffman, 1997; Westervelt et al., 2005).

In summary, the main goal of the present study was to examine the cued odor identification performance of young adults and two age groups of older adults using a wide range of common edible and nonedible olfactory stimuli. To the best of our knowledge, no other study has attempted to assess olfactory identification performance with a large set of ecological stimuli in samples of young and older healthy adults. An interesting finding was a clear decrement in odor identification performance for the group in their 70s. The results of the present study could be useful to help researchers select stimuli of different identification difficulty levels for further studies.

\section{AUTHOR NOTE}

This work was supported by Grant SEJ2004-00752/PSIC from the DGICYT to S.B. and by a predoctoral UNED fellowship to A.F. The authors are very grateful to Lars-Göran Nilsson and two anonymous reviewers for their helpful comments on an earlier version. Correspondence related to this article may be sent to S. Ballesteros, Facultad de Psicología, UNED, Juan del Rosal, 10, 28040 Madrid, Spain (e-mail: mballesteros@psi.uned.es).

\section{REFERENCES}

Alaoui-Ismaïli, O., Vernet-Maury, E., Dittmar, A., Delhomme, G., \& Chanel, J. (1997). Odor hedonics: Connection with emotional response estimated by autonomic parameters. Chemical Senses, 22, 237-248.

Bachoud-Lévi, A.-C., Dupoux, E., Cohen, L., \& Mehler, J. (1998). Where is the length effect? A cross-linguistic study of speech production. Journal of Memory \& Language, 39, 331-346.

Ballesteros, S., Reales, J. M., \& García, B. (2007). The effects of selective attention on perceptual priming and explicit recognition in children with attention deficit and normal children. European Journal of Cognitive Psychology, 19, 607-627.
Ballesteros, S., Reales, J. M., García, E., \& Carrasco, M. (2006). Selective attention affects implicit and explicit memory for familiar pictures at different delay conditions. Psicothema, 18, 88-99.

Ballesteros, S., Reales, J. M., \& Mayas, J. (2007). Picture priming in normal aging and Alzheimer's disease. Psicothema, 19, 239-244.

BARBER, C. E. (1997). Olfactory acuity as a function of age and gender: A comparison of African and American samples. International Journal of Aging \& Human Development, 44, 317-334.

Beaton, A. (1985). Language and laterality. In Left side, right side: A review of laterality research (pp. 109-142). New Haven, CT: Yale University Press.

Bhatnagar, K. P., Kennedy, R. C., Baron, G., \& Greenberg, R. A. (1987). Number of mitral cells and the bulb volume in the aging human olfactory bulb: A quantitative morphological study. Anatomical Record, 218, 73-87.

Bonfils, P., Faulcon, P., \& Avan, P. (2004). Screening of olfactory function using the Biolfa olfactory test: Investigations in patients with dysosmia. Acta Otolaryngologica, 124, 1063-1071.

CAIN, W. S. (1970). Odor intensity after self-adaptation and crossadaptation. Perception \& Psychophysics, 7, 271-275.

CaIN, W. S. (1979). To know with the nose: Keys to odor identification. Science, 203, 467-470.

CAIN, W. S. (1989). Testing olfaction in a clinical setting. Ear, Nose, \& Throat Journal, 68, 316, 322-328.

Corwin, J., Loury, M., \& Gilbert, A. N. (1995). Workplace, age, and sex as mediators of olfactory function: Data from the National Geographic Smell Survey. Journals of Gerontology, 50B, P179-P186.

Cowell, P. E., Turetsky, B. I., Gur, R. C., Grossman, R. I., Shtasel, D. L., \& GUR, R. E. (1994). Sex differences in aging of the human frontal and temporal lobes. Journal of Neuroscience, 14, 4748-4755.

Cuetos, F., Ellis, A. W., \& Alvarez, B. (1999). Naming times for the Snodgrass and Vanderwart pictures in Spanish. Behavior Research Methods, Instruments, \& Computers, 31, 650-658.

Desor, J. A., \& Beauchamp, G. K. (1974). The human capacity to transmit olfactory information. Perception \& Psychophysics, 16, 551-556.

Devanand, D. P., Michaels-Marston, K. S., Liu, X., Pelton, G. H., Padilla, M., Marder, K., et AL. (2000). Olfactory deficits in patients with mild cognitive impairment predict Alzheimer's disease at follow-up. American Journal of Psychiatry, 157, 1399-1405.

DотY, R. L. (1986). Gender and endocrine-related influences upon olfactory sensitivity. In H. L. Meiselman \& R. S. Rivlin (Eds.), Clinical measurement of taste and smell (pp. 377-413). New York: Macmillan.

Doty, R. L. (1989). Age-related alterations in taste and smell function. In J. C. Goldstein, H. K. Kashima, \& C. F. Koopmann, Jr. (Eds.), Geriatric otorhinolaryngology (pp. 97-104). Toronto: Decker.

Doty, R. L., Applebaum, S., Zusho, H., \& Settle, R. G. (1985). Sex differences in odor identification ability: A cross-cultural analysis. Neuropsychologia, 23, 667-672.

Doty, R. L., \& KerR, K.-L. (2005). Episodic odor memory: Influences of handedness, sex, and side of nose. Neuropsychologia, 43, 1749-1753.

Doty, R. L., Marcus, A., \& Lee, W. W. (1996). Development of the 12 -item Cross-Cultural Smell Identification Test (CC-SIT). Laryngoscope, 106, 353-356.

Doty, R. L., Shaman, P., Applebaum, S. L., Giberson, R., SiksorSKI, L., \& RosenberG, L. (1984). Smell identification ability: Changes with age. Science, 226, 1441-1443.

Doty, R. L., Shaman, P., \& Dann, M. (1984). Development of the University of Pennsylvania Smell Identification Test: A standardized microencapsulated test of olfactory function. Physiology \& Behavior, 32, 489-502.

Doty, R. L., Shaman, P., Kimmelman, C. P., \& Dann, M. S. (1984). University of Pennsylvania Smell Identification Test: A rapid quantitative olfactory function test for the clinic. Laryngoscope, 94, 176-178.

Doty, R. L., Snyder, P. J., Huggins, G. R., \& Lowry, L. D. (1981). Endocrine, cardiovascular, and psychological correlates of olfactory sensitivity changes during the human menstrual cycle. Journal of Comparative Physiology \& Psychology, 95, 45-60.

Double, K. L., Rowe, D. B., Hayes, M., Chan, D. K. Y., Blackie, J., CORBETT, A., ET AL. (2003). Identifying the pattern of olfactory defi- 
cits in Parkinson disease using the Brief Smell Identification Test. Archives of Neurology, 60, 545-549.

ENGEN, T. (1988). The acquisition of odor hedonics. In S. van Toller \& G. H. Dodd (Eds.), Perfumery: The psychology and biology of fragrance (pp. 79-90). London: Chapman \& Hall.

Eskenazi, B., CAin, W. S., \& Friend, K. (1986). Exploration of olfactory aptitude. Bulletin of the Psychonomic Society, 24, 203-206.

Finkel, D., Pedersen, N. L., \& Larsson, M. (2001). Olfactory functioning and cognitive abilities: A twin study. Journals of Gerontology, 56B, P226-P233.

Frank, R. A., Dulay, M. F., \& Gesteland, R. C. (2003). Assessment of the Sniff Magnitude Test as a clinical test of olfactory function. Physiology \& Behavior, 78, 195-204.

Frye, R. E., Schwartz, B. S., \& Doty, R. L. (1990). Dose-related effects of cigarette smoking on olfactory function. Journal of the American Medical Association, 263, 1233-1236.

FusARI, A., \& BALLESTEROS, S. (2006). Identification of odors as affected by aging: Normative data and priming effects [Abstract]. Chemical Senses, 31(8), E28.

Jescheniak, J. D., \& Levelt, W. J. M. (1994). Word frequency effects in speech production: Retrieval of syntactic information and of phonological form. Journal of Experimental Psychology: Learning, Memory, \& Cognition, 20, 824-843.

JöNssON, F. U., \& Olsson, M. J. (2003). Olfactory metacognition. Chemical Senses, 28, 651-658.

Kaneda, H., Maeshima, K., Goto, N., Kobayakawa, T., AyabeKanamura, S., \& Saito, S. (2000). Decline in taste and odor discrimination abilities with age, and relationship between gustation and olfaction. Chemical Senses, 25, 331-337.

Kobal, G., Hummel, T., Sekinger, B., Barz, S., Roscher, S., \& WoLF, S. (1996). "Sniffin' Sticks": Screening of olfactory performance. Rhinology, 34, 222-226.

Koenig, O., Bourron, G., \& Royet, J.-P. (2000). Evidence for separate perceptive and semantic memories for odours: A priming experiment. Chemical Senses, 25, 703-708.

Koskinen, S., \& TUORILA, H. (2005). Performance on an odor detection and identification test as a predictor of ortho- and retronasal odor intensity ratings in the young and elderly. Food Quality \& Preference, 16, 383-392.

Larsson, M., \& BäcKMan, L. (1997). Age-related differences in episodic odour recognition: The role of access to specific odour names. Memory, 5, 361-378.

Larsson, M., Finkel, D., \& Pedersen, N. L. (2000). Odor identification: Influences of age, gender, cognition, and personality. Journals of Gerontology, 55B, P304-P310.

Larsson, M., LövdÉN, M., \& Nilsson, L.-G. (2003). Sex differences in recollective experience for olfactory and verbal information. Acta Psychologica, 112, 89-103.

Larsson, M., Nilsson, L.-G., Olofsson, J. K., \& Nordin, S. (2004). Demographic and cognitive predictors of cued odor identification: Evidence from a population-based study. Chemical Senses, 29, 547-554.

LEHRNER, J. P. (1993). Gender differences in long-term odor recognition memory: Verbal versus sensory influences and the consistency of label use. Chemical Senses, 18, 17-26.

LehrNer, J. P., GlÜCK, J., \& LASKa, M. (1999). Odor identification, consistency of label use, olfactory threshold and their relationships to odor memory over the human lifespan. Chemical Senses, 24, 337-346.

Liss, L., \& Gomez, F. (1958). The nature of senile changes of the human olfactory bulb and tract. Archives of Otolaryngology, 67, 167-171.

Liu, H. C., Wang, S. J., Lin, K. P., Lin, K. N., Fuh, J. L., \& Teng, E. L. (1995). Performance on a smell screening test (the MODSIT): A study of 510 predominantly illiterate Chinese subjects. Physiology \& Behavior, 58, 1251-1255.

MuRPHY, C. (1983). Age-related effects on the threshold, psychophysical function, and pleasantness of menthol. Journal of Gerontology, 38, 217-222.

MurPhy, C., \& CAIN, W. S. (1986). Odor identification: The blind are better. Physiology \& Behavior, 37, 177-180.

Murphy, C., Cain, W. S., Gilmore, M. M., \& Skinner, R. B. (1991). Sensory and semantic factors in recognition memory for odors and graphic stimuli: Elderly versus young persons. American Journal of Psychology, 104, 161-192.
Murphy, C., Nordin, S., \& Acosta, L. (1997). Odor learning, recall, and recognition memory in young and elderly adults. Neuropsychology, 11, 126-137.

Nordin, S., Brämerson, A., LidÉn, E., \& Bende, M. (1998). The Scandinavian Odor-Identification Test: Development, reliability, validity and normative data. Acta Otolaryngologica, 118, 226-234.

Nordin, S., Nyroos, M., Maunuksela, E., Niskanen, T., \& TuoRILA, H. (2002). Applicability of the Scandinavian Odor Identification Test: A Finnish-Swedish comparison. Acta Otolaryngologica, 122, 294-297.

ÖBerg, C., Larsson, M., \& Bäckman, L. (2002). Differential sex effects in olfactory functioning: The role of verbal processing. Journal of the International Neuropsychological Society, 8, 691-698.

PARKIN, A. J., \& Russo, R. (1990). Implicit and explicit memory and the automatic/effortful distinction. European Journal of Cognitive Psychology, 2, 71-80.

Parola, S., \& Liberini, P. (1999). Assessing olfaction in the Italian population: Methodology and clinical application. Italian Journal of Neurological Sciences, 20, 287-296.

Price, J. L., Davis, P. B., Morris, J. C., \& White, D. L. (1991). The distribution of tangles, plaques and related immunohistochemical markers in healthy aging and Alzheimer's disease. Neurobiology of Aging, 12, 295-312.

Reales, J. M., \& Ballesteros, S. (1999). Implicit and explicit memory for visual and haptic objects: Cross-modal priming depends on structural descriptions. Journal of Experimental Psychology: Learning, Memory, \& Cognition, 25, 644-663.

Reales, J. M., Ballesteros, S., \& García, E. (2002). Visual-word identification thresholds for the 260 fragmented words of the Snodgrass and Vanderwart pictures in Spanish. Behavior Research Methods, Instruments, \& Computers, 34, 276-285.

Richardson, J. T. E., \& ZUCCO, G. M. (1989). Cognition and olfaction: A review. Psychological Bulletin, 105, 352-360.

Richman, R. A., Wallace, K., \& Sheehe, P. R. (1995). Assessment of an abbreviated odorant identification task for children: A rapid screening device for schools and clinics. Acta Paediatrica, 84, 434-437.

Rovee, C. K., Cohen, R. Y., \& ShlaPack, W. (1975). Life-span stability in olfactory sensitivity. Developmental Psychology, 11, 311-318.

Royet, J.-P., Plailly, J., Delon-Martin, C., Kareken, D. A., \& Segebarth, C. (2003). fMRI of emotional responses to odors: Influence of hedonic valence and judgment, handedness, and gender. NeuroImage, 20, 713-728.

Schemper, T., Voss, S., \& CaIN, W. S. (1981). Odor identification in young and elderly persons: Sensory and cognitive limitations. Journal of Gerontology, 36, 446-452.

SCHIFFMAN, S. S. (1997). Taste and smell losses in normal aging and disease. Journal of the American Medical Association, 278, 1357-1362.

Ship, J. A., Pearson, J. D., Cruise, L. J., Brant, L. J., \& Metter, E. J. (1996). Longitudinal changes in smell identification. Journals of Gerontology, 51A, M86-M91.

Snodgrass, J. G., \& VANDERWART, M. (1980). A standardized set of 260 pictures: Norms for name agreement, image agreement, familiarity, and visual complexity. Journal of Experimental Psychology: Human Learning \& Memory, 6, 174-215.

Suzuki, Y., Yamamoto, S., Umegaki, H., Onishi, J., Mogi, N., FuJISHIRO, H., \& IGUCHI, A. (2004). Smell identification test as an indicator for cognitive impairment in Alzheimer's disease. International Journal of Geriatric Psychiatry, 19, 727-733.

TAKagi, S. F. (1989). Human olfaction. Tokyo: University of Tokyo Press.

Westervelt, H. J., Ruffolo, J. S., \& Tremont, G. (2005). Assessing olfaction in the neuropsychological exam: The relationship between odor identification and cognition in older adults. Archives of Clinical Neuropsychology, 20, 761-769.

Yousem, D. M., Maldjian, J. A., Siddiei, F., Hummel, T., Alsop, D. C., GECKLE, R. J., ET AL. (1999). Gender effects on odor-stimulated functional magnetic resonance imaging. Brain Research, 818, 480-487.

(Manuscript received March 16, 2007; revision accepted for publication January 4, 2008.) 